\title{
EL MONUMENTO IBÉRICO DE MONFORTE DEL CID
}

\author{
MARTÍN ALMAGRO GORBEA \\ Universidad Complutense \\ RAFAEL RAMOS FERNÁNDEZ \\ Universidad de Alicante
}

\section{A Alejandro Ramos Folqués}

\begin{abstract}
Estudio sobre el monumento ibérico del Arenero de Monforte del Cid que está constituido por cuatro elementos independientes: uno escultórico, un toro; y tres arquitectónicos, un sillar con función de plinto, un sillar de gola con función de cornisa y un sillar con función de pilar decorado con falsas puertas. Estos elementos han permitido plantear su reconstrucción dados su hallazgo conjunto y la total correspondencia de medidas entre la base de la gola y el pilar a las que también se adecua la figura del toro que además responde a una misma técnica de tallado y que estilísticamente mantiene una estrecha relación con un determinado prototipo griego perteneciente al arcaismo final y, consecuentemente, anterior a la plena difusión del arte clásico.

Este monumento puede considerarse como una obra local debida a un escultor directa o indirectamente formado en el ámbito griego-oriental y posiblemente realizado en momentos relativamente próximos al año 500 a. de J. C.
\end{abstract}

A fragmented bull and several other pieces of a Iberic monument found in Monforte del Cid (Alicante) are described and studied. They belong to a monumental type called «pilarestela» by one of the authors. The accuracy of the stone-work, and the old date proposed, make it one of the most important monuments of the first moments of the Iberic sculpture.

\section{HISTORIA DEL HALLAZGO}

El día 12 de abril de 1972 Alejandro Ramos Folqués, Director del Museo Arqueológico de Elche, fue informado de que entre las piedras traídas por un camión para la cimentación de una casa de dicha ciudad, en la plaza de Cervantes, esquina a la calle Cura Bascuñana, había una figura escultórica que se consideraba de interés. Tras el examen de la pieza se comprobó que se trataba de una figura zoomorfa esculpida en piedra arenisca caliza. Representaba un bóvido estilizado en posición tumbada con las patas dobladas; presenta una banda vertical estriada en la parte frontal de la cabeza que cae sobre los pliegues del morro; ofrece la boca abierta mostrando la dentadura y, en la parte posterior, la cola está levantada dejando ver una resaltada vulva, por lo que tiene cierto paralelo en la bicha hallada en La Albufereta (RAMOS, e/p). 
Los albañiles de la citada construcción indicaron sobre la procedencia de dicha pieza, que había sido traída por los camiones que abastecían la obra y que cargaban en un arenero del Vinalopó, situado en Monforte del Cid, que les proporcionaba piedra y arena.

Ante el posible interés que el indicado lugar pudiera tener y con la intención de realizar un reconocimiento del terreno, Alejandro Ramos Folqués se trasladó inmediatamente, en compañía de uno de los obreros, a la cantera de referencia, en donde pudo ver los restos de un toro de extraordinaria calidad, $\mathrm{y}$ dos piezas arquitectónicas.

El dueño y el encargado del arenero, informados de la importancia del hallazgo, aceptaron gustosos donar dichas piezas, que fueron trasladadas a Elche y depositadas en su Museo Arqueológico.

El lugar de los hallazgos ya estaba totalmente arrasado, pero por las referencias de quienes allí trabajaban dedujo Alejandro Ramos Folqués la impresión de que aquello pudo ser un lugar cúltico.

Los obreros le informaron de que «otros toros pequeños», como el hallado en la obra, habían sido cargados en camiones, aunque ya no podían recordar su destino; el conservado en el arenero no había sido mandado con la arena a las obras porque por su mayor tamaño pensaron que primero deberían trocearlo. No habían sido descubiertos, sin embargo, restos de construcciones y, según dijeron, no hubo otros sillares ni vestigio alguno de obra arquitectónica edificada, lo que en principio hacía pensar en un monumento a cielo abierto.

Seguidamente se procedió a efectuar un reconocimiento amplio de la superficie del terreno para identificar su contexto arqueológico, pero ni las prospecciones realizadas en las proximidades del lugar del hallazgo ni la exploración de sus alrededores ofreció un solo vestigio, ni un solo fragmento cerámico.

En septiembre de 1980, interesado por la importancia del hallazgo, Martín Almagro Gorbea efectuó un reconocimiento de la zona del hallazgo y obtuvo una importante información complementaria facilitada por Teodoro Fernández Sanz, que trabajaba en la cantera desde la fecha del hallazgo como encargado de la pala mecánica con la que se extraía la arena y que declaró ser el autor de los hallazgos.

Según Teodoro Fernández, los toros hallados por él se trasladaron al Museo de Elche o a Monforte del Cid «sin que se perdiera ninguno». Los transportistas que trajeron a Elche la pieza que sir- vió de indicio para localizar el arenero y el resto del conjunto indicaron que en el edificio entonces en construcción en la plaza de Cervantes de Elche, formando parte de la cimentación, había otros dos toros pequeños como el de referencia y cuya extracción era imposible, ya que en la cantera sólo se aprovecha la grava. También indicó que todos los ejemplares salieron en una extensión de unos $100 \mathrm{~m}$. y que en aquella zona aparecían rodales con cenizas abundantes. También aparecieron dos urnas cerámicas que fueron recogidas y trasladadas al Museo de Novelda por quien dijo ser su director. (En el Museo de Novelda no hay constancia de dichos materiales, según visita personal y confirmación oral de su director.)

Siguiendo estas referencias, aún fue posible localizar, en la margen izquierda del río, los restos del yacimiento, situado debajo de unos campos viñedos, en el extremo nordeste de la actual explotación. En el perfil producido por el corte abierto por la cantera se apreciaba una larga bolsa de ceniza de unos $200 \mathrm{~cm}$. de longitud por 10 de potencia y unos $75 \mathrm{~m}$. más al Este otra de 75 por $20 \mathrm{~cm}$. de potencia y a unos $3 \mathrm{~m}$. de ésta una tercera de unos $25 \mathrm{~cm}$. de longitud por 10 de potencia. Todas estas bolsas de cenizas, interpretables como restos de tumbas o de «busta» de las sepulturas ibéricas (sobre las características de estos tipos de sepulturas ibéricas, probablemente restos de sepulturas tumulares con hoyo para las cenizas construidas sobre el lugar del bustum, ALMAGRO-GORBEA, 1980, 393 y 398; 1983a, 183), parecían estar sobre el suelo natural y quedaban claramente cubiertos por un metro aproximadamente de tierra vegetal, en la que aparecían diversos restos cerámicos e incluso se halló un pequeño fragmento de terra sigillata.

\section{TOPOGRAFÍA DEL YACIMIENTO}

El lugar del hallazgo es un arenero que está situado en la ladera izquierda del río Vinalopó, en un paraje que actualmente es término de Monforte del Cid, a $1.100 \mathrm{~m}$. al Sur del puente sobre este río existente a $4 \mathrm{~km}$. de Aspe, en la carretera de dicha población a Monforte. Las coordenadas aproximadas del yacimiento son $38^{\circ} 21^{\prime} 35^{\prime}$ ' latitud Norte y $2^{\circ}$ 57' 20' longitud Este de Madrid, correspondiendo a la hoja 871 «Elda» del mapa 1:50.000 del Instituto Geográfico Nacional.

Las tareas de extracción del arenero han arrasado una pequeña terraza amesetada existente junto 


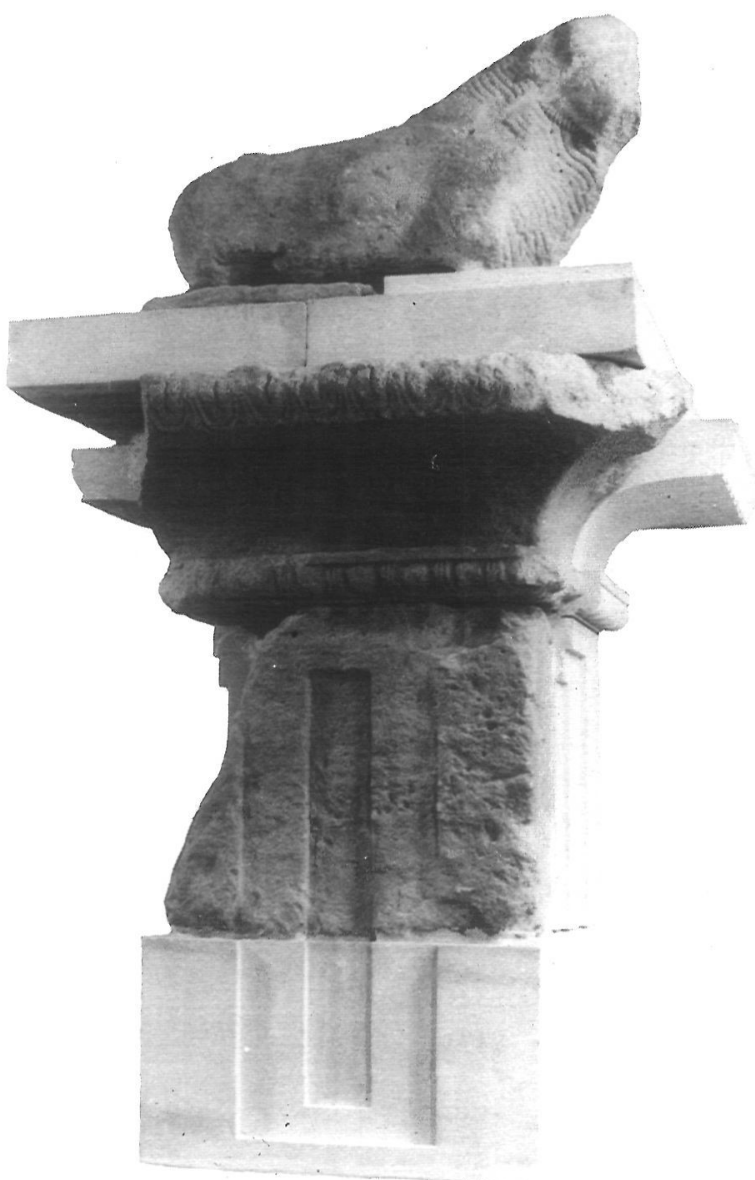

Lám. 1.-Reconstrucción del Monumento.

al río, desmontando en sus aproximadamente cinco metros de altura una superficie de unos cien metros de anchura hacia el Este por una longitud de unos trescientos metros siguiendo el curso del río en su ribera izquierda.

Cerca de este lugar se encuentra Orito, lugar de romería a donde se dirigen los ilicitanos a pie y por el llamado «Camino de Elche» cada 1 de mayo, para peregrinar y orar a la Virgen de Orito, siendo digno de tenerse en cuenta que las romerías actuales mantienen muy viejas tradiciones, que perviven en los santuarios.

Este llamado «Camino de Elche» es uno de los tramos de la Vía Romana de Tarraco a Cartago Nova (MOROTE, 1979, 153), que se debe considerar como de evidente origen prerromano, pues une el yacimiento que nos ocupa con la ciudad ibérica de La Alcudia (RAMOS, 1974; 1975). Además, dicho camino atraviesa las canteras de las que se abastecieron los escultores y canteros del taller existente en dicha ciudad en época ibérica (RAMOS, 1974; sobre la existencia de un taller arquitectónico-escultórico en Elche ALMAGRO-GORBEA, 1980, nota 54), pues tanto las piezas de Monforte como en las de La Alcudia de Elche, están labradas en el mismo tipo de piedra arenisca, como han demostrado los análisis realizados.

En efecto, de los materiales en piedra existentes en el Museo Monográfico de La Alcudia se extrajeron muestras que fueron analizadas por miembros del Instituto de Geología "Albert Lapparent», de París (ECHALLIER-MONTENAT, 1977). Además del estudio macroscópico de las facies, se llevó a cabo el análisis microscópico de las rocas empleadas en las obras escultóricas y arquitectónicas. El estudio de una muestra procedente de un fragmento escultórico informó que se trataba de una molasa calcáreo-arenosa amarilla, conteniendo numerosos fragmentos de cuarzo detrítico de pequeño tamaño y con presencia de fragmentos de foraminí-

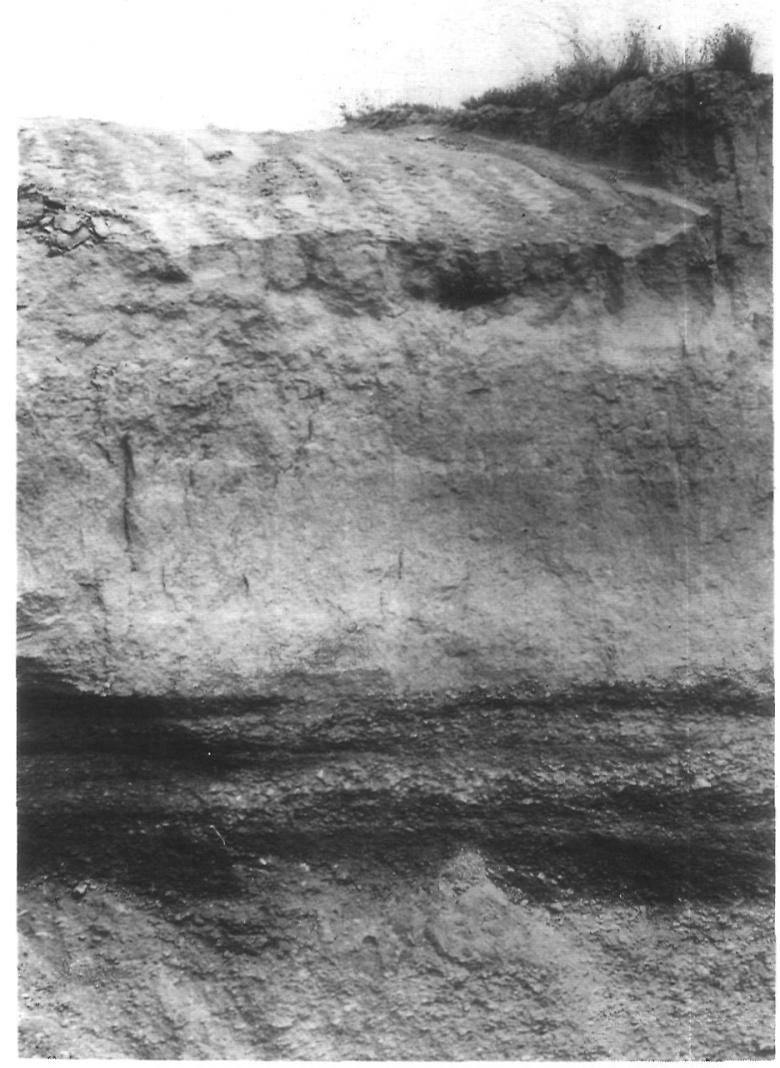

Lám. 2.- Corte dejado en las tareas de extracción de arenas y restos de una incineración todavía apreciable. La fotografía pertenece al momento del descubrimiento del Monumento. 
feros. Tanto la microfacies como la fauna permiten afirmar que la muestra procede de las molasas del Tortoniense Superior que afloran al NE. de Elche, bajo las margas del Mioceno Terminal, en la hoy llamada Cantera Peligros.

Otra muestra estudiada se extrajo de un fragmento arquitectónico y su análisis informó que era una caliza que contenía algo de yeso detrítico y muy numerosos foraminíferos plactínicos así como abundantes fragmentos de equinodermos. Esta muestra procede de las calizas con Globigerinas del «Helveciense» (Mioceno Medio), que no se encuentra en esta región más que en la ladera Sur del Tabayá, en contacto con las calizas margosas del Mioceno Inferior, tanto al NO. de la Vallongas como en el tramo de cabecera del Barranco de San Antón, hoy denominado «Las Canteras».

Es importante hacer constar que todos los restos escultóricos ibéricos hallados en La Alcudia han sido esculpidos en la misma molasa tortoniense, al igual que el toro del Arenero de Monforte, según indica su facies microscópica. Esta roca relativamente blanda se presta bien para su empleo en escultura, pero carece de la resistencia necesaria para utilizarla en obras arquitectónicas. Sin embargo, la caliza «Helveciense» es mucho más resistente, por lo que, ante lo observado, debemos suponer y generalizar que ésta fue preferentemente utilizada en arquitectura mientras que la molasa tortoniense lo fue en escultura, lo que evidencia un conocimiento profundo de los materiales constructivos, aunque éste fuera de tipo empírico.

Pero en cualquier caso, lo que aquí interesa recalcar es que ambas canteras, abastecedoras de los yacimientos ibéricos de la comarca, se encuentran por el «Camino de Elche», que comunica directamente la ciudad ibérica de La Alcudia con el yacimiento de Monforte del Cid.

El yacimiento está situado, por lo tanto, en el estratégico cruce del Vinalopó por el «Camino de Elche», punto que en la antigüedad debió ser un importante cruce de caminos, pues en él confluirían la vía que corría por la zona litoral con la vía que penetraba hacia el interior; ésta subía por el valle del Vinalopó hasta unirse cerca de Fuente la Higuera a la vía Hereklea o Camino de Aníbal (SILLIERES, 1977, 31 s.), en lo que sería la mansión de $A d T u$ rres, topónimo que hace referencia quizá a la existencia de otros monumentos funerarios turriformes y en donde se situaba el inicio de la numeración de uno de los tramos de la Vía Augusta (MOROTE,
1979, 153-b). Además dicha Vía al unir Cádiz y el Valle del Guadalquivir con las llanuras del Levante peninsular pasando por Cástulo, los valles del Guadalmena y del Jardín, los Altos de Chichilla, el Corredor de Montesa y Játiva, debió jugar el papel de principal eje cultural y de comunicaciones de la Península Ibérica en la época Prehistórica (ALMAGRO-GORBEA, 1978, 100, fig. 2).

Por lo tanto, el yacimiento de Monforte del Cid ocupaba un punto estratégico de gran importancia entre las tierras costeras del Sureste de la Península Ibérica y las vías de penetración hacia el interior a través de las cuales se lograba la mejor comunicación tanto con las ricas zonas mineras de Cástulo y el Valle del Guadalquivir como con las llanuras de la zona de Valencia.

Este dato es de enorme trascendencia para la interpretación del monumento de Monforte. Su situación estratégica en su cruce de caminos resulta semejante a la de otros monumentos paralelizables y cada vez mejor conocidos en la cultura ibérica (ALMAGRO-GORBEA, 1980; íd., 1982a; íd., 1982b; íd., 1983a), lo que unido a su casi segura aparición en una necrópolis ibérica, explica la aparición de los restos de Monforte del Cid, más que en relación con un santuario, como monumentos conmemorativos de tipo funerario que aprovechaban un destacado y estratégico cruce de vías de comunicación para resaltar su importancia.

\section{DESCRIPCIÓN DEL MONUMENTO}

El monumento de Monforte del Cid, según los datos recogidos, está formado actualmente por cuatro elementos independientes, uno escultórico, un toro estante y tres arquitectónicos, un sillar con función de plinto, un sillar de gola con función de cornisa y un sillar con función de pilar decorado con falsas puertas. Las noticias referentes al hallazgo no han permitido la situación exacta de aparición de estas piezas, por lo que no existe total seguridad de que los citados elementos correspondan a un único monumento, pero las circunstancias del hallazgo y las características y dimensiones de las piezas permiten aceptar esta hipótesis como la más verosímil, asumiéndose en consecuencia y procediéndose a su descripción y estudio correspondiente. Todas las piezas se conservan actualmente en el Museo Arqueológico Municipal de Elche. 


\section{Escultura de toro de bulto redondo}

Dimensiones: Altura de lo conservado: $65 \mathrm{~cm}$. Longitud máxima: $127 \mathrm{~cm}$.

Grosor máximo: $30 \mathrm{~cm}$.

Representa un toro alzado de tamaño algo menor del natural con la cabeza ligeramente vuelta hacia la derecha y claramente elevada sobre la línea del lomo. Las orejas y el morro y el ojo derecho están prácticamente perdidos. El ojo derecho, esculpido en profundidad, ofrece una órbita redondeada con el párpado diferenciado y cuatro arrugas en su parte superior que acentúan la forma almendrada del mismo.

La testud ofrece una doble banda recta a modo de tiara de oreja a oreja, pero que puede ser una estilización del pelo del animal. El cuello, ligeramente vuelto, ofrece una serie de arrugas entre 6 y 15 , señaladas a base de incisiones onduladas paralelas que bajan de la cerviz y forman bajo la cabeza una gran papada prolongada, a base de surcos más cortos, por delante de las patas delanteras. La más próxima a la cabeza presenta trazos transversales a modo de barba del animal. El cuerpo es proporcionalmente estrecho y no se conserva más que el arranque de las extremidades por rotura. Las nalgas aparecen separadas por un biselado y entre ellas se ha labrado una cola corta y de sección rectangular.

El tratamiento del volumen de la figura es de buena calidad, con planos apenas diferenciados gracias a un modulado suave y continuo de gran sentido plástico, en el que destaca el recurso a ciertas estilizaciones muy efectistas, como las líneas que forman las arrugas del cuello. En conjunto, esta pieza, por su sensación de realismo y por su calidad plástica, puede situarse entre las mejores realizaciones del Arte Ibérico, pues lo que le falta de espontaneidad lo compensa con un perfecto empleo de los recursos más característicos de la mejor escultura ibérica.

\section{Sillar de gola decorado con ovas en el filete $y$ el baquetón}

Dimensiones: Altura: $46 \mathrm{~cm}$.

Longitud: $170 \mathrm{~cm}$.

Grosor: $82 \mathrm{~cm}$.

Este sillar ofrece un lado completo y dos medios lados, por lo que corresponde a la mitad de una hi-
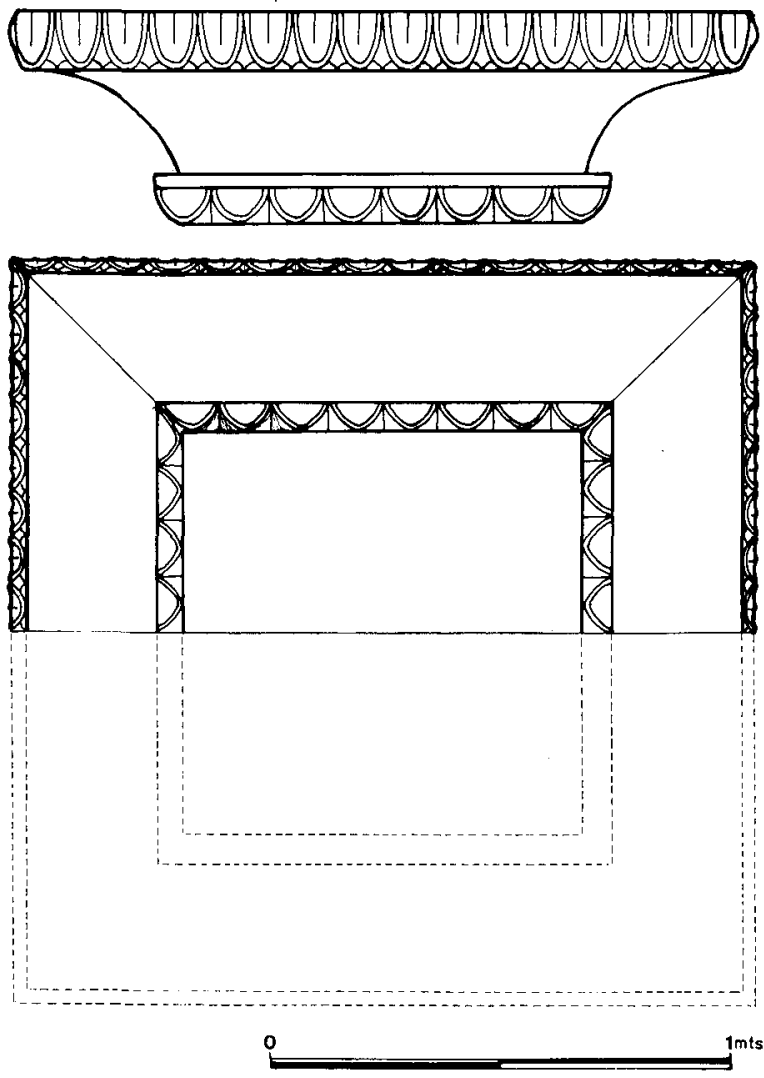

Fig. 1.-Sillar de gola con función de cornisa.

lera que estaría formada por dos sillares semejantes contrapuestos, que constituirían la moldura arquitectónica del monumento, formada por una gola enmarcada entre sus correspondientes filete. y baquetón.

El filete está decorado con una moldura de sección convexo-cóncava decorada con dieciséis ovas por lado, de forma alargada, con una moldura en sus bordes y una incisión central, quedando separados unas de otras por flechas.

Bajo el filete se inicia la nacela, de curva suave y de escaso desarrollo vertical con una proporción de 2 ó 3 respecto al vuelo. Es totalmente lisa. 


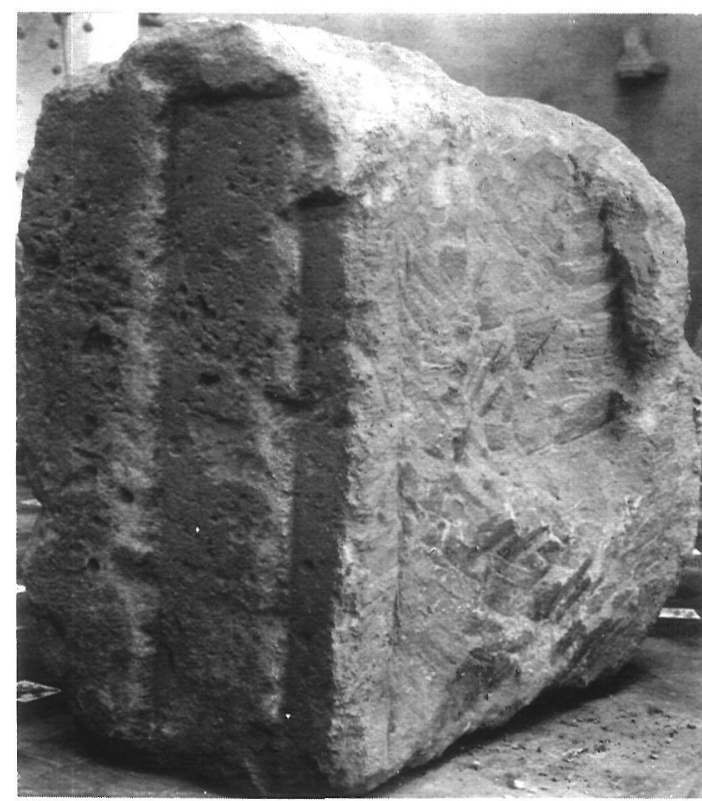

Lám. 3a.-Lateral e interior del sillar con función de pilar decorado con falsas puertas.

La nacela descansa sobre un baquetón en forma de cuarto de bocel formado por un listel plano bajo el que corre una moldura constituida por 8 ovas con molduras en sus bordes y el interior muy abultado separados por ángulos diedros a modo de flechas. De la parte inferior de las ovas arranca una superficie vertical plana que coincidiría con el sillar sustentante, pues corresponde a las dimensiones del pilar que se describe a continuación.

La labra es de buena calidad y bien cuidada, tanto en lo que se refiere a la regularidad y proporciones del trazado como a la ejecución plástica de las ovas.

\section{Sillar de un pilar decorado con falsas puertas}

Dimensiones: Altura: $73 / 4 \mathrm{~cm}$.

Longitud: $88 \mathrm{~cm}$.

Grosor: $44 \mathrm{~cm}$.

Este sillar, como el anterior, corresponde a la mitad de una hilera que estaría formada por dos sillares semejantes contrapuestos.

Ofrece una decoración de «falsas puertas» a base de una serie de dos superficies escalonadas que enmarcan el rectángulo central rehundido. Estos ele-

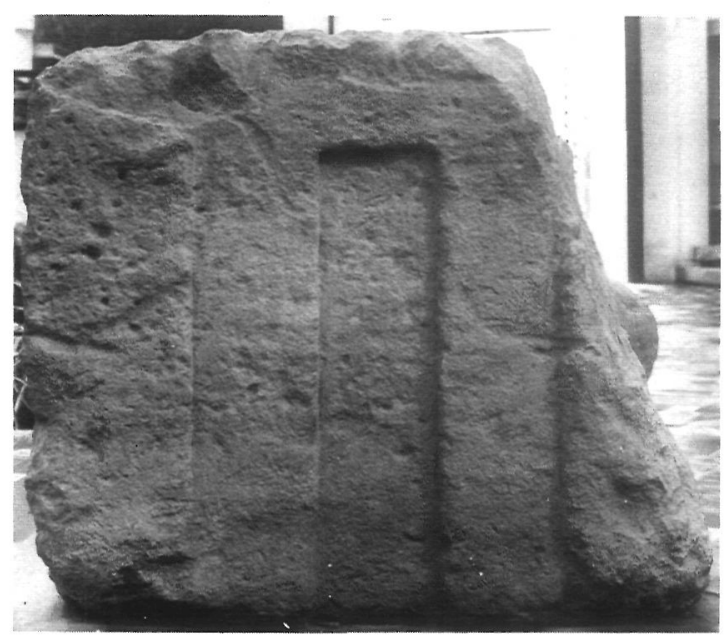

Lám. 3b.-Exterior del sillar con función de pilar.

mentos aparecen en los laterales y en la parte superior, mientras que por la parte inferior da la sensación de que continuaría en otro sillar o acabaría sobre una superficie plana horizontal.

El lado mayor ofrece esta organización completa, mientras que las dos caras laterales presentan la misma disposición, pero sólo en una mitad, ya que la otra mitad estaría labrada sobre otro sillar simétrico que formaría el resto de esta hilada.

La cara interior aparece toscamente rebajada con hazuela, salvo la superficie próxima a los bordes que está más cuidada para lograr una buena anathyrosis con el sillar gemelo. El centro ofrece un grueso rebajado cuya función se puede poner en relación con dicha anathyrosis mejor que con los agujeros circulares que ofrecen alguno de estos monumentos.

\section{Fragmento de sillar perteneciente tal vez a un plinto}

Dimensiones: Altura: $21 \mathrm{~cm}$.

Longitud máxima conservada: $64 \mathrm{~cm}$. Anchura: $42 \mathrm{~cm}$.

El fragmentario estado de esta pieza, rota en sus dos extremos longitudinales, sólo permite apreciar 


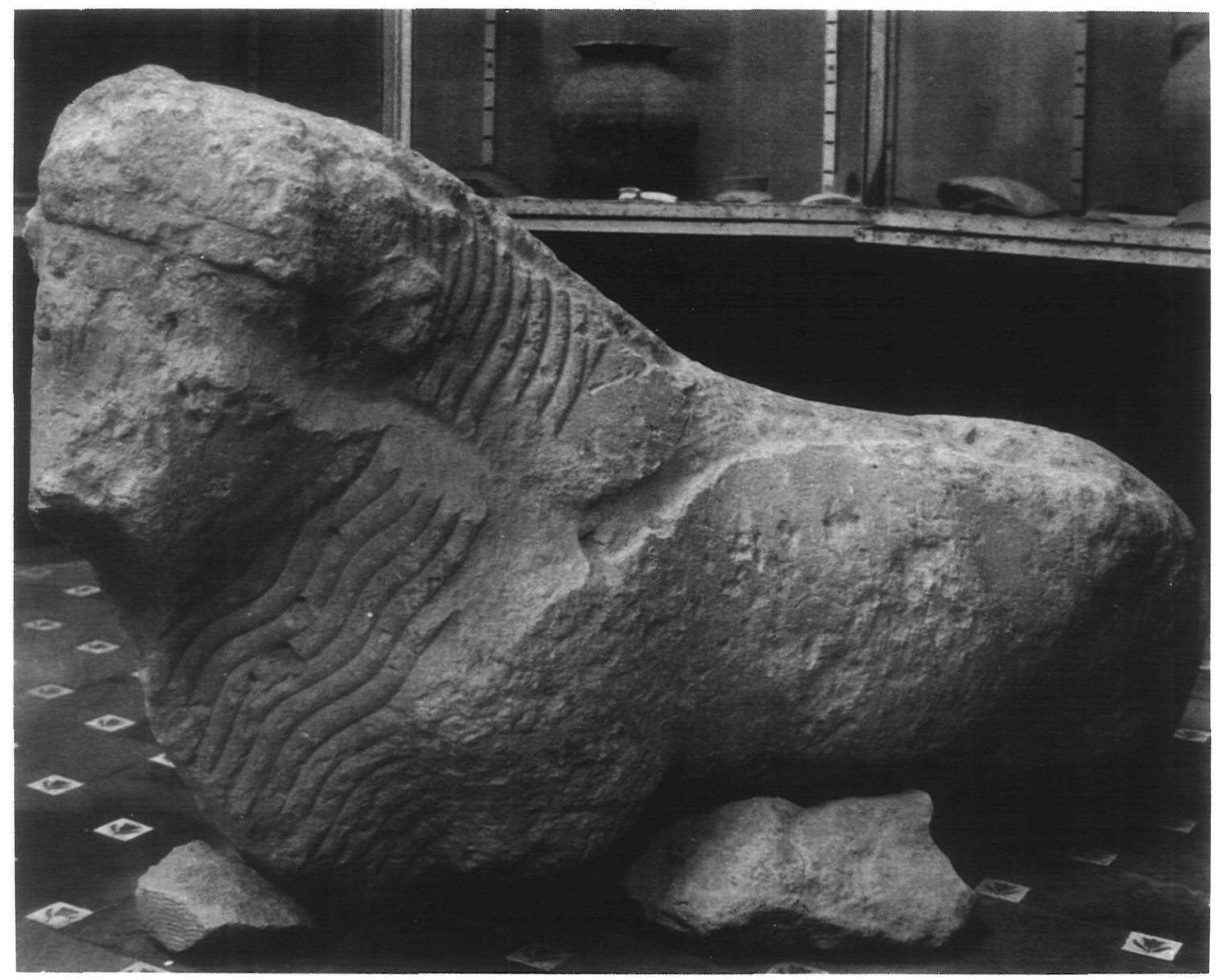

Lám. 4a.-Toro.

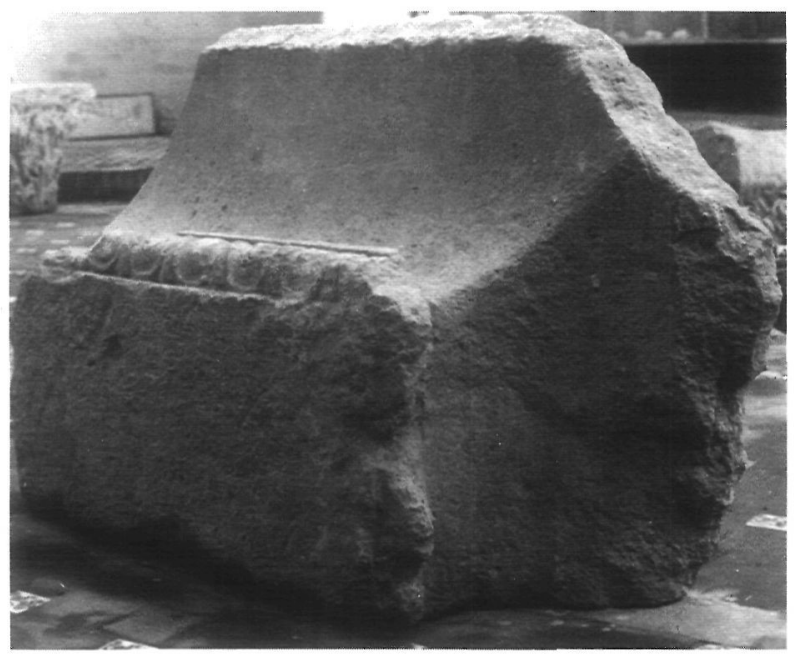

Lám. 4b.-Sillar de gola con función de cornisa. su forma longitudinal con dos escalones en los lados conservados, de $7 \mathrm{~cm}$. el superior y el inferior de $14 \mathrm{~cm}$. de alto, por un reentrado de $7 \mathrm{~cm}$. de ancho en relación al anterior, por lo que pudo ser un podio o pedestal para la escultura sobre estante de unos $28 \mathrm{~cm}$. de anchura.

\section{RECONSTRUCCIÓN}

Los elementos conservados del monumento permiten plantear su reconstrucción con cierta verosimilitud. Aunque ya se ha señalado que la pertenencia de las cuatro piezas al mismo monumento no es segura, por no haber sido obtenidas en excavación científica, su hallazgo conjunto y la total correspon- 

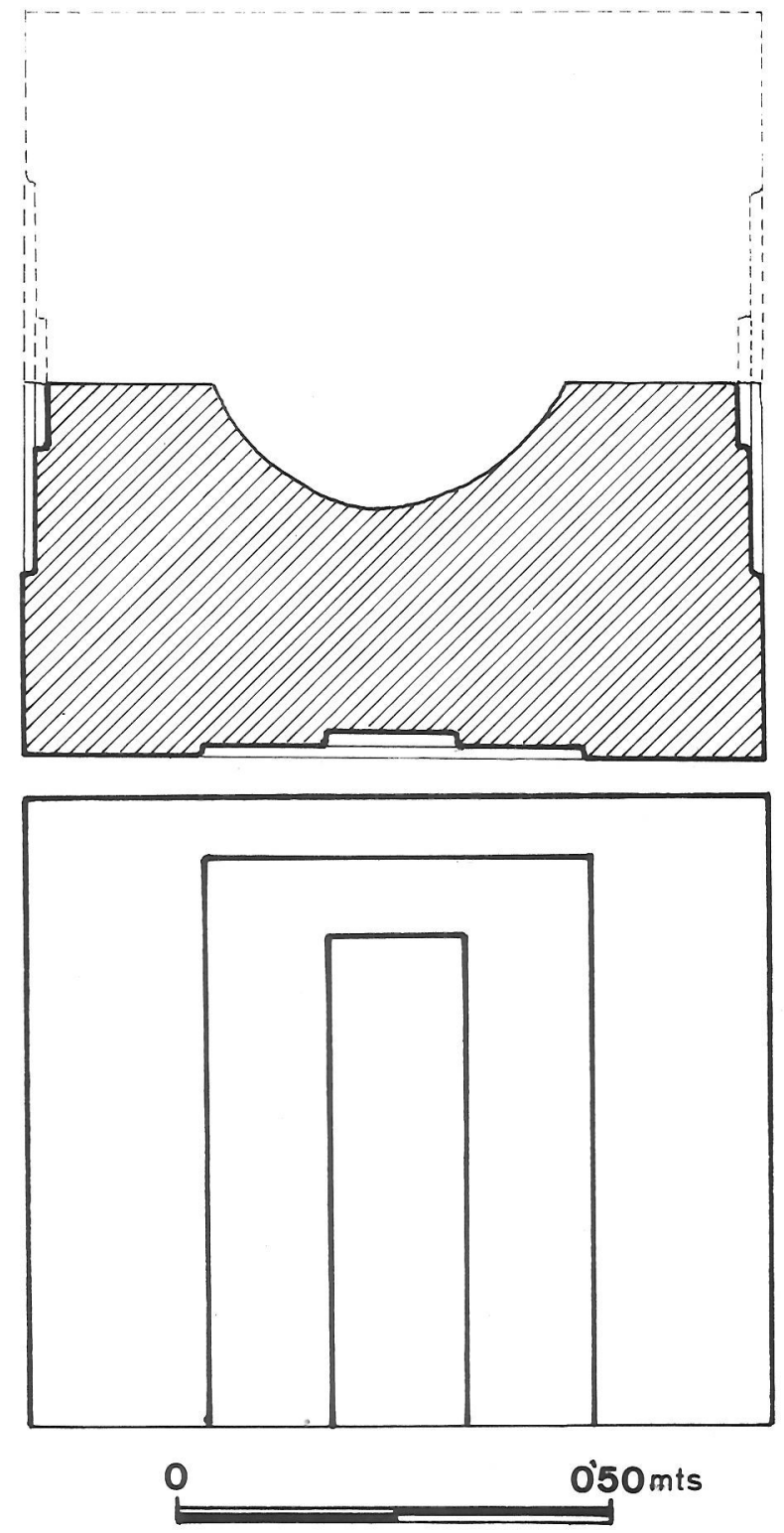

Fig. 2.-Sillar con función de pilar.

dencia de medidas entre la base de la gola y el pilar, permiten deducir con casi absoluta certeza que ambos elementos se corresponden. Sólo con mayor incertidumbre se puede suponer que el toro también perteneció al mismo conjunto monumental, basándose en las dimensiones y en la técnica de su modelado. Por último, el posible plinto también se puede atribuir al conjunto, si bien con más prevención, en base a sus dimensiones y a una perfecta coherencia con la estructura hipotética del monumento.

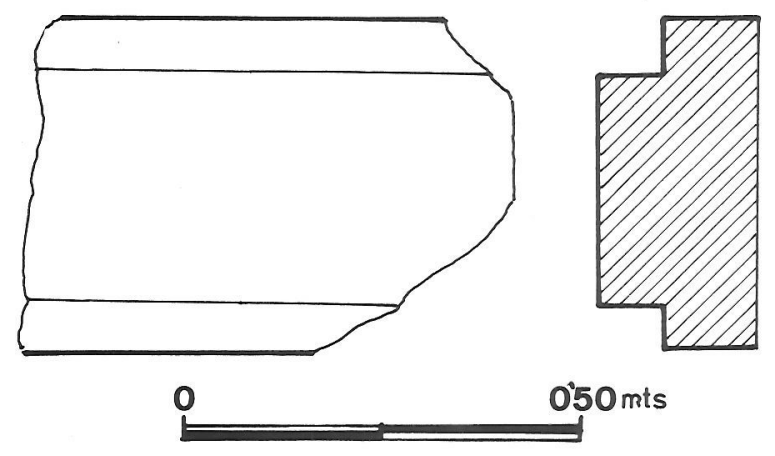

Fig. 3.-Sillar con función de plinto.

La reconstrucción de la estructura originaria del monumento se basa en que el sillar de gola constituye por sí solo la mitad de la hilada a la que pertenecía, ya que ofrece un lado completo y dos medios lados, por lo que se complementaría con otra pieza simétrica semejante.

Además, la anchura de la base de la gola coincide con la anchura del sillar del pilar, por lo que se puede deducir que se apoyaría directamente sobre éste. Como este sillar conservado es, a su vez, la mitad de una hilada, ésta se complementaría con otro semejante y simétrico, unidos por sus caras internas. Incluso es lógico suponer que la disposición de los dos sillares de la gola debió ser contrapuesta a la de los del pilar de base para evitar que las junturas coincidieran, ya que al quedar éstas perpendiculares se lograría una mayor estabilidad. Así, la asociación cornisa de gola sobre pilar cuadrado con falsas puertas queda perfectamente establecida.

Más dudoso es precisar si el pilar de falsas puertas se complementaría con otra hilera por debajo de altura semejante, pues la proporción de la falsa puerta resulta excesivamente baja $y$, además, una cornisa arquitectónica como la gola exige ir dispuesta a una determinada altura, como mínimo por encima de los ojos.

Como la altura del sillar es de $88 \mathrm{~cm}$. y la altura a que se puede colocar la gola no bajaría de $80 \mathrm{~cm}$., existe una diferencia aproximada de por lo menos $100 \mathrm{~cm}$. Como hipótesis más probable dada la proporcionalidad que evidencia el monumento, se puede suponer un complemento de sillar que diese a la falsa puerta una proporción ancho/alto adecuada, aproximadamente de $1: 2$, de $3: 5$ o de $2: 3$, lo que daría unas alturas totales de $176,1460132 \mathrm{~cm}$., respectivamente. A falta de criterios más objetivos se ha optado por esta última por ser suficientemente lógica. 
Aún se debería complementar esta altura hipotética con una base escalonada, que constituiría la verdadera sepultura, del tipo tumular escalonado habitual en la cultura ibérica del Sureste (ALMAGROGORBEA, 1890 y 1983a) por lo que la altura total del pilar superaría fácilmente la altura de una persona quedando la escultura del toro situada sobre la gola por encima de los 200 a $250 \mathrm{~cm}$. y resaltada por el plinto escalonado cuyas dimensiones coinciden aproximadamente con las de la escultura.

De este modo el monumento de Monforte del Cid representa el primer caso conocido de la disposición original de las esculturas ibéricas exentas lo que constituye un importante enriquecimiento de nuestros conocimientos sobre este problema, que se puede considerar como prácticamente resuelto, al mismo tiempo que contribuye decisivamente a resolver el problema de la función, significado y cronología de dichas esculturas cuyo papel en la cultura ibérica es tan destacado (Almagro-Gorbea, 1983b).

\section{Medidas y proporciones}

La cuidadosa ejecución del monumento de Monforte del Cid evidencia un trazado y ejecución sujetos a medidas y proporciones. Sin embargo, no es fácil deducirlas de los restos conservados pues éstos son incompletos y no siempre es posible obtener medidas exactas, dado el estado de conservación y la imprecisión que ofrecen las medidas teóricas al materializarlas en la labra de la piedra.

Por ello, sólo a modo de aproximación, se procede a dar las medidas conocidas en centímetros con su verosímil equivalencia en una unidad métrica teórica. Por este procedimiento se puede llegar a deducir las dimensiones medias de dicha unidad métrica y su error respecto a la medida en centímetros observada, aunque los resultados sólo se puedan considerar aproximados dadas las características del monumento:

\section{CM./}

CM. PALMOS PALMO

Plinto:

\begin{tabular}{|c|c|c|}
\hline Altura total............................. & 21 & 3 \\
\hline Escalón inferior .................. & 14 & 2 \\
\hline Escalón superior .................. & 7 & 1 \\
\hline 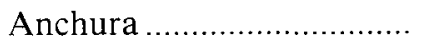 & 42 & 6 \\
\hline 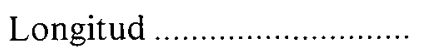 & $>64$ & $>9$ \\
\hline
\end{tabular}

CM. PALMOS PALMO

Gola:

Altura total.....................

Altura filete...

$\begin{array}{ccc}46 & 6 & 7,6 \\ 13,5 & 2 & 6,7 \\ 22,5 & 3 & 7,5 \\ 3 & 0,5 ? & - \\ 7,5 & 1 & 7,5 \\ 1 & - & - \\ 170 & 24 & 7,0 \\ 37 & 5 & 7,4 \\ 6,5 & 1 ? & - \\ 88 & 12 & 7,3\end{array}$

Altura nacela ....................

Altura volante baquetón ...

Altura base baquetón.

Longitud

Vuelo nacela

Vuelo baquetón

Longitud base.

Pilar:

Altura total.

$74 \quad 10$
88

Longitud total

$88 \quad 12$

Ancho «falsa puerta».......

Alto «falsa puerta»...........

Ancho escalón inferior .....

Alto escalón inferior ..........

Ancho escalón exterior .....

$14,5 \quad 2$

$58 \quad 8$

$15 \quad 2$

669

21

7

7,4

7,3

7,2

7,2

7,5

7,3

7

Alto escalón exterior .........
El resultado parece confirmar la tendencia al uso de una unidad de medida de $7,15 \mathrm{~cm}$. de mediana, $7 \mathrm{~cm}$. de moda y $7,2 \mathrm{~cm}$. de media. Esta unidad se puede interpretar como un palmo o $1 / 4$ de un pie de unos $28 / 29 \mathrm{~cm}$. que se debe, en principio, considerar relacionado con el documentado en otros monumentos ibéricos, como el de Alcoy (ALMAGROGORBEA, 1983c), 175).

Dada la imprecisión de las medidas, más complejo y difícil es averiguar las proporciones y la posible modulación del momento. Su existencia parece probada por elementos como el ritmo de los escalones de la «falsa puerta» $3,2,2,2,3=12$ palmos; o la relación entre el ancho y el alto de las ovas del filete $=1: 1$ lo que explica su altura de $13,5 \mathrm{~cm}$. que es, muy aproximadamente, 1:12 de su longitud $=164 \mathrm{~cm}$. También se puede observar la proporción entre las diversas partes de la gola, por ejemplo entre la altura de la nacela y la del baquetón: 5:3. Igualmente quedan proporcionados los dos escalones del plinto, en relación $1: 2$, o la semejante altura de éste y el ancho del escalón exterior de la falsa puerta, $21 \mathrm{~cm} .=3$ palmos, pero no es posible, con los insuficientes elementos conservados, precisar más en esta difícil cuestión. 


\section{ANÁLISIS TIPOLÓGICO}

Los elementos constituyentes del monumento de Monforte del Cid ofrecen unas características tipológicas y estilísticas que merecen un detenido examen pues permiten precisar el origen y la cronología de este singular conjunto. Un análisis objetivo lo más exhaustivo posible de estos aspectos resulta del mayor interés dada la novedad que supone este monumento cuya valoración obliga a relacionarlo con otros elementos paralizables de la Cultura Ibérica, hasta ahora nunca bien interpretados, lo que supone un incremento de su indudable interés intrínseco. Por otra parte, la diversidad de elementos constituyentes obliga a profundizar en el complejo origen de estos monumentos y, por extensión, en el de la Cultura Ibérica dentro de la cual resultan característicos.

Los diversos elementos integrantes requieren un tratamiento individual, dadas las características peculiares y el origen diverso de cada uno de ellos; por ello se procede a analizarlos uno a uno en primer lugar, dándose al final el estudio correspondiente al conjunto.

\section{La escultura del toro}

La figura de toro que constituiría el remate del monumento representa una de las más importantes piezas de la cultura ibérica, pues une a su buena conservación relativa una gran calidad estética y el interés del conocimiento de su funcionalidad.

El modelo realista y cuidado del cuerpo, las patas evidentemente exentas, el tratamiento estilístico de los pliegues del cuello, el detalle de la barba y de los rizos sobre la frente y la actitud de ladear ligeramente la cabeza para romper la rigidez y simetría de la figura hacen que esta escultura de toro se pueda considerar una de las mejores representaciones de este animal realizada en la plástica ibérica.

Esta figura corresponde a un modelo de toro que tradicionalmente se ha considerado de origen griego, según se deduciría de la cronología (FERNÁNDEZ, 1941, 517 y 523) o romano (GARCÍA BELLIDO, 1943; BLANCO, 1962, 184) si bien nunca se ha llegado a estudiar su filiación ni a precisar sus paralelos.

Sus características permiten considerarlo dentro de un grupo de figuras de toro, que ha sido definido en el trabajo esencial de Chapa como «de carác- ter realista... normalmente.... en pie», denominándose «segundo grupo helenizante» (CHAPA, 1980, 846-7), dentro del cual, como se verá más adelante, debe considerarse como un ejemplar muy destacado.

En dicho estudio se define como tipo A de toro este «segundo grupo helenizante», para diferenciarse de un tipo B» de interior sin desbastar... echados, con la cabeza mirando al frente y la boca curiosamente entreabierta dejando ver unos dientes rectangulares en una actitud amenazante totalmente falta de realismo» (CHAPA, 1980, 803 s.).

Esta diferenciación tipológica resulta acertada pero no así la terminología empleada que es equívoca en lo que respecta al supuesto helenismo del tipo B.

Al tipo A corresponderían además de 5 piezas de Cabezo Lucero (1), las del Cerro de los Santos (CHAPA, 1980, 296), la del Llano de la Consolación 2 (PARIS, 193, 140 f. 109; FERNÁNDEZ, 1953, 203 1. 7, 1), Arjona (GARCÍA BELLIDO, 1971, 1. 82-3), La Guardia (CHAPA, 1980, 457), el «heroon» de Porcuna (Inédita. Agradecemos a J. González Navarrete el acceso a esta pieza), «Provincia de Jaén» (NICOLINI, 1973, 83, f. 58), Montemayor (Inédita. Agradecemos a A. M. ${ }^{a}$ Vicent la autorización para estudiar esta pieza), Alcalá del Río (FERNÁNDEZ CHÍCARRO, 1957, 55 1. 15), Cerro de los Infantes 1 y 2 (HERNÁNDEZ DÍAZ, SANCHO y COLLANTES DE TERÁN, 1951, 5961) y Osuna 1 y 2 (GARCÍA BELLIDO, 1943, 1. 28-9 y f. 107). A éstas habría que añadir la escultura posteriormente hallada en Coimbra del Barranco Ancho (Inédita en el Museo de Jumilla), un fragmento de El Cigarralejo (Agradecemos a E. Cuadrado el permitirnos el examen de esta pieza conservada en su colección procedente de la necrópolis de El Cigarralejo), y ésta de Monforte del Cid, aparte de los fragmentos de más dudosa identificación por su mal estado de conservación (CHAPA, 1980, 800).

Dentro del tipo A, el toro de Monforte se relaciona especialmente con el de Cabezo Lucero 1, por el tratamiento más realista de pliegues, la existencia de barba y de rizos sobre la frente. Sin embargo

(1) FERNÁNDEZ, 1941. La denominación de las piezas es la siguiente: Cabezo Lucero 1 (C. L. 1)= f. 3 y 16; C. L. $2=$ fig. $6-8$; C. L. 3 , f. 17 ; C. L. $4=$ f. 13 ; C. L. $5=$ f. 15 . Resulta incierta la clasificación de las piezas recogidas en las figuras 2 y 14, aunque por la proximidad estilística del conjunto podrían considerarse dentro de este grupo A. 


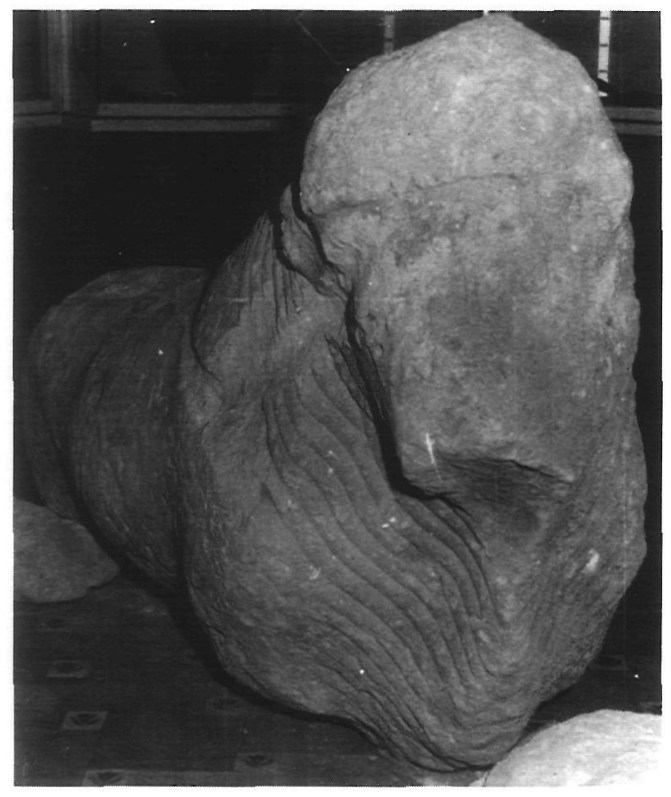

Lám. 5a.-Aspecto frontal del toro.

la. característica de la cabeza girada aparece en la escultura del toro tumbado de Osuna, que, evidentemente, es una pieza especial dentro de esta serie por tratarse de un sillar de esquina estilísticamente de carácter evolucionado (ALMAGRO GORBEA, 1980).

Los ejemplares de Monforte y Cabezo Lucero 1 , quedan relacionados además por constituir las mejores creaciones de este tipo de toro ibérico en cuanto a su calidad plástica y su técnica de remodelado, lo que evidencia que se trata de los ejemplares teóricamente más próximos al hipotético modelo griego.

Esta circunstancia plantea la necesidad de precisar esta relación entre modelo griego y creación ibérica para establecer el origen y filiación artística de estas piezas, deducir su cronología y enmarcarlas dentro del contexto cultural del mundo ibérico y colonial del Sureste de la Penísula Ibérica.

Este tipo de toro ibérico, tan definido, resulta verosímil suponerlo copia o derivado de un prototipo griego que debió servir como modelo, si bien éste nunca ha sido identificado. Por tanto, resulta interesante examinar los tipos de toro ibérico.

Para ello es importante valorar varios elementos estilísticos que dan a esta pieza su peculiaridad:

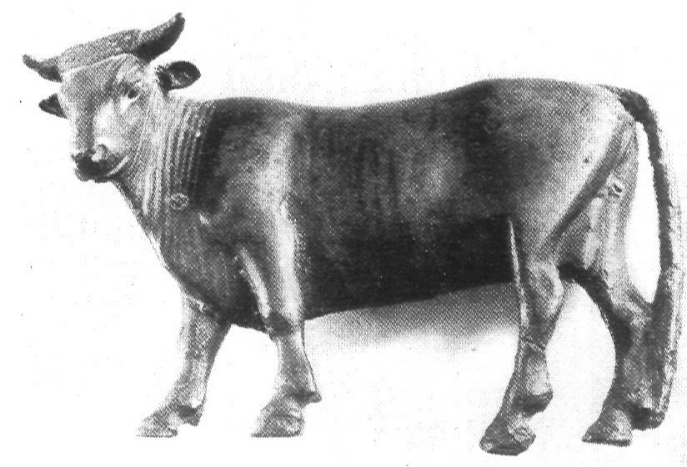

Lám. 5b.-Relieve de bronce del Museo Diocesano de Ciudadela. (Foto: E. KUKAHN).

la postura estante y exenta, el tratamiento plástico de la anatomía $\mathrm{y}$, especialmente, dos detalles aún más significativos, la cabeza ligeramente doblada a un lado y la estilización de los pliegues del cuello, que dan a este tipo de figura su máxima personalidad.

La convención estilística de representar los pliegues del cuello a base de líneas paralelas sinuosas es de seguro origen oriental, pues queda bien documentado en numerosos ejemplares por todo Oriente.

En los relieves de Tell Halaf es frecuente recurrir a este procedimiento con las figuras de diversos animales, entre ellos el toro (OPPENHEIM, 1983, 1. 19a 23a, y 266).

Lo mismo evidencia la glíptica, en la que existen numerosos ejemplares aducibles desde época muy antigua (MOORTGAT, 1940, 153-6, 463, 554, $630,651,744$, etc.), y que influirá en la glíptica arcaica griega, aunque en este campo dicha convención perdure hasta época tardía.

Pero son las páteras repujadas de metal y los marfiles sirio-fenicios los que parecen constituir el precedente directo de esta representación convencional del toro explicando su aparición en el arte chipriota y griego orientalizante, como otro elemento más de tantos que desde el Oriente pasaron al arte griego de forma semejante. 
La lista de piezas de bronce con representaciones de toro es relativamente amplia y ha sido actualizada recientemente a propósito de la pátera del $\mathrm{Mu}$ seo de Teherán 15.192 (CULLICAN, 1970, 71 s. 1. VIII, 2.).

Comprendería dos piezas de Rheneira en el Museo de Miconos (E. KUNZE, s/a, 159-60 n. 35), otras dos piezas de Olimpia (Olimpia IV n. ${ }^{\circ} 884$ : Daux, 819, f. 11; CULLICAN, 1970, 70 f. 2), otra del cerámico (KUBLER, s/a, 20 s. 1.162 y $201 \mathrm{f}$. 5; HERMANN, 1966, J. d. I. 81), otra protochipriota del Louvre (GJERSTAD, 1946 II p.), otra pieza en el mercado de antigüedades de Teherán (CULLICAN, 1970 f. 5, 75), otras dos de Dali de estilo fenicio (GJERSTAD, 1946, VII y XI), y una tercera de oro procedente igualmente de Chipre de estilo egiptilizante (GJERSTAD, 1946, XII), y en relación con ésta, la pátera y el cuenco de la tumba Bernardini (CURTIS, 1919, 17, 18 y 19).

Otro grupo de bronces relacionable con estas páteras son los escudos y placas repujados aparecidos en el Idalión de Chipre. En estas piezas, la citada convención con la representación del animal se repite (E. KUNZE, s/a, s. 1. 34, 39, 47, 49), evidenciando su relación iconográfica de las representaciones de las páteras metálicas, relación igualmente presente en alguna otra pieza como el fragmento de bronce del Museo de Berlín (E. KUNZE, s/a, n. 1 51 b.; AZARPAY, 1968, 19, 52, 57). Este motivo aparece igualmente en el Mediterráneo Occidental, en el ámbito orientalizante etrusco de Caere (PARETTI, 1947, 1. 39; CAMPOREALE, 1977, 101-2 1. 35), de claro influjo fenicio.

Finalmente se puede señalar las imitaciones en pasta vítrea de El Kuru (DUNHAN, s/a, 93 n. ${ }^{\circ} 666-$ 7 f. 31c. 1. 44a).

También los marfiles ofrecen un fenómeno comparable al de los bronces repujados con los que estilísticamente quedan a veces tan relacionados.

Esta estilización del toro aparece perfectamente usada con cierto realismo con los marfiles de Enkomi del siglo XII a. d. C. (BERNAT, 1982, 37-8, 1. 30) y su continuidad se aprecia en los marfiles sirios del siglo IX-VIII (MALLOWAN and HERRMANN; 1974, III, 1. 1, 68-9 f. 13; 1. 105-7, 113; BARNETT, 1975, f. 26, 35, 65, 67 y 101-6), y fenicios desde el siglo X a. de C. (BARNETT, 1982, 46. 1. 24a) en adelante (BARNETT, 1975, 48 f. 19), siendo, en cambio, excepcional en los marfiles asirios (MALLOWAN and DAVIES, 1970, 1. 31-33).
Se halla documentada también en el ámbito feniciooccidental (AUBET, 1979, f. 4, 5 y 8; BONSOR, 1899, f. 44; íd, 1928, 47, 1. 18), donde la presencia de este recurso estilístico en la eboraria es muy importante ya que explica la paralela aparición tanto en cerámicas (REMESAL, 1975, 3 s.), como en la plástica fenicia peninsular orientalizante de donde se adaptó a la ibérica. En efecto piezas tan señaladas como el toro de Porcuna (BLANCO, 1960, 37 40 1. 56-7; CHAPA, 1980, 480-3 f. 4, 90), evidencian el conocimiento de esta convención por un camino independiente y anterior al que aquí se examina, constituyendo un precedente orientalizante que ayudaría a facilitar la introducción y arraigo del posterior influjo helénico.

Desde el mundo oriental este recurso estilístico debió pasar pronto a Grecia. Su fuerza gráfica explica su temprana aparición en obras de arte menor, especialmente en glíptica y cerámica, para sólo posteriormente ser asimilado en la escultura, donde este convencionalismo pierde paulatinamente su carácter gráfico y ofrece una clara tendencia a ganar realismo y sentido plástico dentro del progreso naturalista de la escultura griega a lo largo del Período Arcaico.

En la glíptica este sistema de representar el toro aparece ya en algunas piezas cretenses y micénicas (FURTWANGLER, 1900, 1. VI 10-11 y 1. III, 5051), que, junto a los tipos orientales, pueden explicar los ejemplos geométricos (A. BRANDT, 1968, n. $\left.{ }^{\circ} 125\right)$. Por influjo fenicio (ZWIERLEIN-DIEHL, 1969, n. ${ }^{\circ}$ s. 132 y 141), dentro del período orientalizante este elemento se debió difundir y resulta ya característico en la época arcaica, especialmente en los escarabeos griegos (FURTWAGLER, 1900, 1. VI, 39, 44, 51 y 52; VII $25,27-8,35,43$; VIII, 3, 58; ZWIERLEIN-DIEHL, $1969, \mathrm{n}^{\circ}{ }^{7}$ 79. 48), asi como en sus copias etruscas (ZAZOFF, 1968, 1. 2, 2.), lo que confirmaría su origen oriental dejando de representarse paulatinamente a partir del final del estilo severo (FURTWANGLER, 1900, 1. VIII, 41, 46, 47; IX, 19; XI, 31 y 32. Para la evolución de esta representación de este animal ZWIERLEINDIEHL, 1900, 1. 38 n. ${ }^{\circ} 167-171$ y 178, $77 \mathrm{s.}$ BRANDT, 1968, n. $^{\circ}$ s. 302-312), aunque por la comodidad y eficacia gráfica de esta convención explique su aparición incluso con algún ejemplar romano republicano (FURTWANGLER, 1900, 1. XXVIII, 65; XXIX, 45; ZAZOFF, 1975, n. ${ }^{\circ} 670-$ b, 142-3; ZAZOFF, 1970, n. ${ }^{\circ} 530$ s.). 
Relacionadas estilísticamente con la glíptica, las acuñaciones monetarias, por su abundancia y buena cronología, también ofrecen un buen campo para el estudio de las representaciones del toro y de los convencionalismos empleados (REGLING, 1924; FRANKE and HIERMER, 1964; JENKINS, 1972).

El eco orientalizante se aprecia en las estilizaciones muy convencionales a que se recurre en las más antiguas piezas como las estáteras de electrón de Mileto del período 620/580 a. de C. (BABELON, 1900, 2, 1, 40 y 77; REGLING, 1924, n. ${ }^{\circ} 11$ y 20), pero pronto se aprecia el influjo del pleno arcaismo, como en las estáteras lidias de Creso (561-546 a. de C.) que ofrecen la convención estilística del cuello perfectamente desarrollada (REGLING, 1924, n. ${ }^{\circ}$ 55), convención que se generaliza en la segunda mitad del siglo VI a. de C., paralelamente a su estudio y desarrollo en la escultura del bulto, mostrando una organización curvilínea y paralela característica, que aparece desde Jonia (por ejemplo, en Samos: BMC Ionia, 1. 34), a la Magna Grecia (como los tetradracmas de Sibaris con el toro con cabeza vuelta (BABELON, 1900, 2, 1, 2.089-2.099) y de Siris (BABELON, 1900, 2, 1, 2.083) fechables ca. $550 / 530$ y las imitaciones de Crotona de ca. 510 a. de C. (SNG England II the Lloyd Collection n. ${ }^{\circ}$ 631), cada vez con el sentido plástico y realista más desarrollado sin perder su claro valor decorativo.

En este mismo período aparecen paralelamente los rizos decorativos sobre la frente, los párpados señalados e incluso una roseta en la testuz en un didracma de Atenas de ca. 575-525 a. de C. (JENKINS, 1972, n. ${ }^{\circ} 66$ ), elementos que ofrece igualmente la plástica ibérica.

Pero es, sobre todo, en la transición del siglo VI al $\mathrm{V}$ a. de $\mathrm{C}$., correspondiendo al final del arcaísmo y durante el estilo severo cuando se documentan los ejemplos más frecuentes de este convencionalismo que paulatinamente se modifica siguiendo la tendencia realista del arte griego (como ejemplos bien característicos pueden considerarse las piezas tracomacedónicas de Orrkeskioi del 520-500 a. de C., Ichnai del 500-480 a. de C., Edonoi 520-480 y Derrohls 520-480 (FRANKEN and HIRMER, 1964, n. ${ }^{\circ} 376,382,386$ y $\left.388,1.123-127,95-6\right)$, así como algunas acuñaciones de Samos del 520-500 a. de C. (íd. n. ${ }^{\circ} 612,1.182,133$ ) y Lesbos del 520-480 a. de C. (REGLING, 1924, n. ${ }^{\circ} 158$ ). Así a partir de la segunda década del siglo $\mathrm{V}$ a. de $\mathrm{C}$. comienza a sua- vizarse esta estilización, perdiendo su carácter gráfico originario. En Messana, del 489-480. cfr. FRANKE und HIRMER, n. ${ }^{\circ} 50,1.16$ p. 43 (tetradracmas de Catania de antes del 476 a. de C.; íd. n. ${ }^{\circ} 66,1.66$, p. 64; tetradracma con representación de una escultura de toro sobre pedestal de Dikaia ca. 500-475), etc.), o tendiendo a desaparecer hacia el segundo cuarto del siglo (por ejemplo, en Gela hacia el 490 a. de C. Cfr. FRANKE und HIRMER, 1964, 1. 55-56), con una clara transición que evidencian numerosas cecas (en Poseidonia, ca. 450: FRANKE und HIRMER, 1972, $\mathrm{n} .{ }^{\circ} 62,123$, etc.), que, frente a la actitud normal generalmente predominante (JENKINS, 19, n. ${ }^{\circ} 89.104-15$, etc.), se debe interpretar como resultado de los intentos de estudio del movimiento del arcaísmo final.

A partir de la segunda mitad del siglo $\mathrm{V}$ a. de C. en adelante no es frecuente el empleo de este recurso estilístico (FRANKE und HIRMER, 1964, 1. 876-8, Thurioi 420-330 a. de C.; 1. 110, Neapolis, ca. 440-360 a. de C.; 1. 122, Liboica, ca. 411 al 146 a. de C.; 1. 143, Corcira, ca. 420-400 a. de C.; 1 . 194, Tarso, ca. 420-380 a. de C.; 1. 199, Cicico, ca. 450-400 a. de C.), pues ha sido totalmente superado en el desarrollo del Arte Clásico, aunque perduró en algunas cecas, normalmente periféricas, pero ya con un estilo totalmente diferente de los ejemplares arcaicos (así en Chipre ca. 450 a. de C., JENKINS, 1972, n. ${ }^{\circ} 228$ ); Gortyna, ca. 400 a. de C. (JENKINS, 1972, n. ${ }^{\circ}$ 260): Gela, ca. 440-405 a. de C.; FRANKEN und HIRMER, 1964, 1. 57; JENKINS, 1972, 373, 335, 412 y 437, etc.), lo que se explica por la eficacia gráfica de esta convención como se ha señalado a propósito de la glíptica. Así aparece este convencionalismo en la moneda helenística (en la Liga Epirota, ca. 234 a. de C. (JENKINS, 1972, n. $^{\circ}$ 548), en Eretria, 196-290 a. de C. (JENKINS, 1910, 1. 57-8, p. 143-5; CRAWFORD, 1974, n. ${ }^{\circ}$ 5), hasta en denarios como el de L. Valerius Acisculus, del 45 a. de C. (CRAWFORD, 1974, n. ${ }^{\circ}$ 474/1). Incluso en la moneda hispánica también es frecuente (VIVES y ESCUDERO, 1924, 1. 6, 14, $90,98,110,147-577$, y puede explicarse junto al influjo de tipos helenísticos y romanos, por su paralelo conocimiento en el campo de la escultura.

En la decoración cerámica la representación del toro es relativamente frecuente, evidenciándole en sus inicios claros influjos orientales, para paulatinamente ir modificándose siguiendo la evolución general del arte griego. 
En Chipre, este tipo de estilización del toro, muchas veces con gran sentido decorativo que domina totalmente sobre la representación de la anatomía, se desarrolla a partir del período Chiprio-Arcaico I (750-600 a. de C.) (KARAGEORGIS, 1965, J. d. I 80 , p. 1 s. f. 1-16), en que, coincidiendo con el influjo orientalizante de donde procede el modelo del toro, se hace frecuente la representación de este animal (KARAGEORGIS, ct. DES GRAGNIERS, $1974,114-115,131$ a 133 y $238-1.140$, donde se comenta el influjo de tejidos orientales). Esta característica se mantiene hasta el estilo «Bicromo rojo II (V)» de fines del siglo VI al V. a. de C., en que se evidencia un influjo de las cerámicas de la Grecia Oriental (GJERSTAD, 1948).

Pero frente al marcado influjo orientalizante de la cerámica chipriota es en la decoración pintada de la cerámica griega donde mejor se puede apreciar la evolución del toro y de los recursos estilísticos utilizados por los artistas griegos para su representación.

En las producciones cerámicas de la Grecia Oriental se observa cómo las convenciones estilísticas para representar los bóvidos, como la característica línea del cuello, surgen a fines del siglo VII a. de C. en el Período Orientalizante, coincidiendo con su primera aparición en las representaciones plásticas que se conocen en metal.

Ya se ha señalado cómo el origen de este recurso estilístico es claramente oriental (KARDARA, $1978,68)$, y a través de las importaciones debió ser eonocido y pronto imitado en las producciones cerámicas griegas contemporáneas.

Así, se encuentra esta decoración en la crátera de estilo de Camiros de Constantinopla (SCHEURLEER, 1936, 1. 6 f. 20 p. 31), en los productos de Quios (WALTER-KARYDI, 1973, 1. 94, n. ${ }^{\circ} 745$; ARIAS, 1962, 1. 28 p. 280), y grupos relacionados (SALVIAT, 1978, 1. 48, 8 y 50, 13), de Rodas (E. WALTER-KARYDI, 1973，1. 130，1.043; 132, 1.068; KARDARA, 1978, f. 6; SCHIERING, s/a, 1. 15, 1 y 2), de la Jonia Septentrional (WALTERKARYDI, 1973, 1. 49, 440 b.), ya de mediados del siglo VI a. de C., cuyo estilo se refleja en el estilo de Klitias (ARIAS, 1962, n. ${ }^{\circ} 87,1.54$; MINTO, $1960,1.31$ y 32), perdurando esta convención hasta inicios del siglo $\mathrm{V}$ a. de $\mathrm{C}$. en los sarcófagos de Clazomene (COOK, 1981, 103).

Esta estilización es más rara en otros centros como Corinto (PAYNE, 1931, 70, n. ${ }^{\circ} 4,1.9,1 ; 11$, $1 ; 23,4$ y 16, 9, etc.), donde sólo aparece a partir del Corintio Antiguo (PAYNE, 1931, 1. 21, 1; 22, $4 ; 23,5$ y 25,4$)$, pero sí está presente en algunas ánforas calcídicas (RUMPF, 1927, 1, 8. 116 y 117. No ofrecen el detalle de las líneas en el cuello algunos toros de la 1.8 y el de la $1.36, \mathrm{n}^{\circ} 17 \mathrm{y}$ aparecen con todo detalle en las hidrias de la Colección Castellani y del Louvre E 696 Cl.P. de la COSTE MESSELIERE, 1936, 1. 10, 3 y fr. 7). Aunque ya se ha señalado cómo esta representación del tipo de toro de cuello decorado con múltiples incisiones paralelas también se difunde en la cerámica ática a partir del siglo VI a. de C., es interesante observar su evolución y cronología dentro de los grandes avances logrados por los pintores áticos. Para ello es sumamente gráfico comparar el toro de Klitias en el Vaso François (Vid. infra n. ${ }^{\circ} 92$ ), con el ánfora bilingüe de Boston 99538 con Heracles conduciendo un toro (ARV 4, 12; ABV 225, 6; COHEN, 1978, 186 s. 1. 35), obra de Lissipides y Andokides, para comprender la profunda transformación ocurrida en los decenios centrales del siglo VI a. de C.

Esta ánfora de Boston permite contrastar el animal en figuras negras pintado por Lissipides y su adaptación a figuras rojas por el Pintor de Andokides (ARV 4, 12), siendo evidente el rápido avance logrado en la representación de este animal en los vasos de figuras rojas (ANDREAE, 1962, $145 \mathrm{~s}$. y especialmente $155 \mathrm{~s}$.).

A partir de inicios del siglo $\mathrm{V}$ a. de $\mathrm{C}$., este tipo de toro convencionalista con tratamiento gráfico que aún mantienen los artistas del siglo VI a. de C., como el Pintor de Nicostenos (ARV 125, 15), o el Pintor de Copenhague a inicios del siglo $\mathrm{V}$ a. de $\mathrm{C}$. (ARV 257, 9), se transforma con los grandes pintores del estilo severo como Brigos (ARV 369, 6), Douris (ARV 210, 172), o el Pintor de Berlín (ARV 206, 126), cuya innovación representa la llegada del pleno clasicismo.

Pero, aunque estos campos iconográficos son esclarededores, es, en definitiva, en la plástica donde debe buscarse el auténtico prototipo griego que debe considerarse como modelo de este tipo A de toro ibérico. Por ello merece la pena deternerse a examinar los documentos conservados más cercanos a este tipo de toro ibérico.

La figura de toro posante con grandes pliegues paralelos en el cuello constituye, al parecer, una innovación en el campo de la escultura documentada en relieves arquitectónicos a partir del Arcaismo Medio en los años centrales del siglo VI a. de C. Característica es la representación del rapto de Euro- 
pa del tesoro de los Siconios en Delfos, fechada hacia el 560 a. de C. (COSTE-MESSELIERE, 1936, 153 s. 1. 8; íd., 1957a 1. 40; BOARDMANN, 1978, 1. 208, 3). Igualmente es bien conocida la metopa con el mismo tema del templo Y de Selinunte, fechable hacia el $550 \mathrm{a}$. de $\mathrm{C}$., esto es, muy ligeramente posterior (LANGLOTZ, 1963, 1.8 p. 57), con la cabeza del toro vuelta hacia el espectador.

Este tratamiento estilístico del cuello del animal tan característico aparece, con un sentido más decorativo, en el toro atacado por un león y una leona de la Acrópolis de Atenas, fechado ca. 550-540 (BOARDMANN, 1978, 8,. 191; SCHUCHART, 1940, f. 3), recurso aún no utilizado en otra pieza comparable de ca. 570-560 (BOARDMANN, 1978, f. 190; SCHUCHART, 1940, f. 2), ni en el «Moscóforo» de la Acrópolis de Atenas (SCHIERING, $1958,1.5)$, lo que parece indicar que fue hacia mediados de siglo cuando se produce la introducción de este detalle en la escultura ática. El uso final se vislumbra en el templo arcaico de Delfos (COSTEMESSELIERE, 1957, 1. 145), de ca. 520-510 a. de C., que anuncia la estilización de suaves líneas que ofrecen las figuras de toro de las metopas del tesoro de los Atenienses en Delfos (COSTE-MESSELIERE, 1957, 1. 144; y especialmente íd., 1957b, 22-6; 66-9) fechable ca. 500 a. de C. En época posterior a estos ejemplos, los escultores áticos del período clásico crean una figura de toro ya sin recurrir a las arrugas en el cuello como evidencian las metopas del templo de Zeus en Olimpia (TREU, 1897, 1. 36, 4) que a su vez dieron paso a las creaciones de este animal de los grandes escultores clásicos como Mirón (RICHTER, 1950, 211) y Fidias (BROMMER, 1977, 1. 48-9 y 53-4) en las que se evidencian el triunfo del naturalismo realista del Arte Clásico en la representación de este animal, superándose definitivamente el recurso a las estilizaciones convencionales del Período Arcaico.

La ausencia de esta estilización en los toros del templo de Atenas en Assos (CLARKE, BACON und KOLDEWEY, 1902, 1. 149 f 9, etc.; EAA Atlante dei complessi figurati, 1. 14), fechado ca. 550-525 a. de C., evidencia, aparte de un evidente arcaismo de este conjunto escultórico, que la evolución señalada en la escultura ática pudo no ser totalmente uniforme en toda Grecia. Pero un relieve de Paros, fechado ca. 500 a. de C. (KONTOLEAR, 1965, 348 s. 1.5 y 7), manifiesta que dicha evolución fue bastante general, incluso en lugares provinciales. Lo mismo confirma el relieve con toro atacado por un león que decora la base de una estela hallada en Loryma de inicios del siglo $\mathrm{V}$ a. de $\mathrm{C}$. (PFUHL und MOVIUS, 1977, 17, 1. 8, n. ${ }^{\circ} 25$ ), cuya cabeza, cuernos y la actitud del toro permiten relacionarlo con el toro representado en una escena semejante en un árula de terracota de Centuripe, fechada ca. $500 \mathrm{a}$. de C., y en la que se ha señalado un influjo joniooriental (LANGLOTS, 1963, 65, 1. 32).

El examen de las pequeñas figuras en bronce, exentas o aplicadas a vasos, también confirma la validez general de la evolución señalada. Los pequeños bronces geométicos, orientalizantes y arcaicos son muy estilizados, tanto las figuras aplicadas a vaSOs (HERRMANN, 1966, 1. 42-54 y 63), como las exentas (HEILMEYER, 1976, 1. 14 s., etc.), y carecen de los característicos pliegues en el cuello. Éstos sólo comienzan a aparecer, salvo en alguna decoración grabada como en la coraza de Olimpia (SCHEFOLD, 1971, 28, 5), en figuras más avanzadas de inicios del Arcaismo (íd., íd. 1. 98, 160-1. Aunque se fecha ca. 600 aparecieron con materiales de época clásica) y debieron perdurar hasta el inicio del Período Clásico (COMSTOCK and VERMEULE, 1971, 56), como evidencian los dedicados por inscripciones en los santuarios de Kabiros-Tebas (SZANTO, 1890, 1. 14; WOLTERS und BRUNS, 1940, 36 s.; SCHWALTZ, 1980) (2) o de Heralimenia en Perachora, donde se ofrece una clara tendencia a ganar finura en el modelado anatómico y perder las características estrías del cuello hacia inicios del siglo $\mathrm{V}$ a. de C. (PAYNE, 1931, 136 1. 43, $3 \mathrm{y}$ 43, 4).

Entre los pequeños bronces, un interés especial ofrecen las figuras de bóvido de mejor calidad, como las utilizadas como aplique en los vasos de bronce, especialmente cráteras y trípodes. Algunas ofrecen el detalle de la estilización de las arrugas del cuello, pero otros tienen incluso la actitud de la cabeza ligeramente girada y, en general, ofrecen una tendencia a lograr un buen modelado que permite precisar los avances hacia el naturalismo del período clásico.

En este sentido, se debe tener en cuenta las vacas del trípode de Metaponto (JUCKER, 1966, 1. 45, 2 y 44) fechado ca. 550 a. de C. (ROLLEY, 1969,

(2) En la rica serie de figuras de este santuario el motivo de estrías en el cuello aparece a partir de época arcaica, n. ${ }^{\circ} 185$ y 195 s., y a fines del arcaismo se combina con la tendencia a dar movimiento girando la cabeza, $n .^{\circ} 295,303 \mathrm{~s}$., desapareciendo totalmente en época clásica. 
f. 81, p. 173, n. $^{\circ}$ 2), obra de la Magna Grecia, en la que las proporciones aún son macizas y de aspecto general pesado, aunque se esfuerza por lograr una impresión del movimiento. Con ellas se debe relacionar la pieza de Artemis Ortia en el Museo de Esparta y otra del Louvre $\mathrm{Br} 4524$, de modelado algo más avanzado, pero con el mismo esquema (RICHTER, 1930, 21; ROLLEY, 1969, 173-4), procedente igualmente de Esparta. Más estilizadas resultan las vacas adosadas al cuello de la crátera de Trebenische, fechadas ca. 525-500 (FILOW, 1927, f. 35 a, b y c, y lám. VII), que ofrecen la cabeza girada con más naturalidad y un tratamiento anatómico más realista, aunque la cabeza y testuz ofrezcan una estilización aún tosca y exagerada, en especial en el reticulado de la testuz.

Respondiendo al mismo esquema, la pieza de Ciudaleda (Menorca) (KUKAHN, 1973, 440, f. 1 y 2), curiosamente casi desconocida entre los estudiosos, pero de particular importancia en este caso por su procedencia, presenta ya un modelado suave y unas proporciones muy próximas a la realidad características de los avances del Arcaísmo Final, fechable al acabar el siglo VI a. de C.

La cabeza aparece enormemente ladeada y ni el reticulado de la testuz ni el modelado del cuello con surcos paralelos alteran la sensación de naturalidad de esta pieza, que resulta por ello particularmente próxima al toro de Monforte del Cid y demás ejemplares ibéricos relacionables.

Este hecho aún se precisa mejor si se examina la serie de pequeños bronces de bóvidos de fechas algo posteriores conocidas actualmente.

La vaca de Delphos, marchando con la cabeza recta, es de naturalismo casi plenamente conseguido, apenas alterado por las finísimas estrías que marcan el cuello y que se mantienen como pervivencia final de este detalle estilístico que también ofrecían los bóvidos del tesoro de los Atenienses en Delfos (COSTE-MESSELIERE, 1957b. Por ello, esta pieza ha sido acertadamente fechada ca. 500-490 a. de C. (ROLLEY, 1969, 172-3, f. 181).

Con esta pieza se ha relacionado otra del Heraión de Argos, de modelado algo más tosco, pero con los surcos aún marcados en el cuello, pieza que ya ha sido fechada a inicios del clasicismo.

Las piezas de semejante calidad y ya de cronologia posterior a inicios del siglo $\mathrm{V}$ a. de $\mathrm{C}$. ofrecen un modelado aún más suave $\mathrm{y}$, dentro de la diversidad de tendencias, un dominio general del volumen y de la anatomía del animal que las aparta definiti- vamente de la pieza aquí en estudio. Se puede considerar como ejemplo una pieza en el Comercio de Antigüedades en 1950 (ROLLEY, 1969, f.79-80), otra figura del Metropolitan Museum que ha sido relacionada con la obra de Mirón (Bull. Metr. Museum, 1921, 34 s., f. 5) y la magnífica vaca del Cabinet de Medailles cuya cronología hoy se coloca en la segunda mitad del siglo V. a. de C. (RICHTER, 1930, 22, 1. 32).

El toro y el toro atacado por leones de Vouni evidencian la perduración en algún centro local de la estilización del cuello a base de surcos hasta mediados del siglo V a. de C. (ROLLEY, 1967, n. ${ }^{\circ} 95$ y 96), pero el modelado realista de estas figuras se aparta definitivamente del estilo del toro de Monforte del Cid.

Tras el análisis de la escultura y de los bronces aún cabe examinar la coroplastia. En el período arcaico no son frecuentes los vasos toriomorfos (MAXIMOVA, 1977, 107-8 y 195, f. 37; HELDRING, 1981 , no recoge ningún vaso toriomorfo) los existentes parecen responder al tipo de toro atacado (MOT, 1904, 221, f. 8-9).

El vaso en forma de cabeza de toro del Museo Británico procedente de Caminos, que se ha considerado de tipo jonio (MAXIMOVA, 1977, 1. 19, n. ${ }^{\circ} 77$, p. 172), ofrece el detalle del cuello marcado por numerosas arrugas curvilíneas paralelas, detalle que no ofrece los vasos semejantes del Antiquarium de Berlín (MAXIMOVA, 1977, 1. 23, n. ${ }^{\circ}$ 93) ni del Louvre, de seguro taller y procedencia rodia (MAXIMOVA, 1977, 1. 27, n. ${ }^{\circ}$ 104).

El análisis realizado de los paralelos iconográficos y estilísticos de la escultura de Monforte del Cid ha permitido comprobar la estrecha relación con un prototipo griego que debió servir como modelo. Dicho modelo se puede considerar perteneciente con seguridad al Arcaismo Final, mejor incluso que al inicio del Estilo Severo, siendo, en cualquier caso, anterior a la plena difusión del Arte Clásico.

La precisión del taller o escuela originaria resulta mucho más problemática. El toro de Monforte del Cid recoge innovaciones que pueden atribuirse a la iniciativa artística de los talleres escultóricos áticos, pero que igualmente debieron ser desarrollados en otras áreas, especialmente la Jonia y la Magna Grecia, sin olvidar su repercusión en los pequeños bronces espartanos y suritálicos.

Sólo por motivos culturales, ajenos en principio a los datos que ofrece la pieza, pero no a su contexto cultural, caracterizado por la componente colo- 
nial greco-oriental, concretamente jonio-focense, que tan importante papel tuvo en la helenización de las áreas del Sureste (ALMAGRO GORBEA, 1983a, 455 ss.; íd., 1982c, 432-442; CHAPA, 1982, 374391 ), se podría suponer que el prototipo procediese de un taller jonio o greco-oriental, que aunque peor conocidos, continuaron la gran tradición escultórica de inicios del arcaismo, adoptando, tal vez con cierto retraso, las mismas convenciones estilísticas (PFUHL y MÖBIUS, 1977, 1. 8). Y, en concreto, el papel de Focea ha sido repetidamente señalado a propósito de su influjo en la plástica del Mediterráneo Occidental (LANGLOTZ, 1966; ALMAGRO GORBEA, 1982c, 434 s.; CHAPA, 1982).

La imprecisión en la localización del taller repercute en la fijación de la cronología del modelo y, por tanto, del monumento de Monforte del Cid. Las características estilísticas de esta pieza permiten atribuirla al Arcaismo Final y una fecha todavía dentro del siglo VI a. de C., en torno al 500 a. de C. como máximo, parecería teóricamente la más ajustada, pues no parece posible, en ningún caso, ni remontarla más allà del último cuarto del siglo VI a. de C. ni rebajarla más acá del primero o segundo decenio del $\mathrm{V}$ a. de $\mathrm{C}$.

Sólo cabe, frente a esta cronología, valorar la imprecisión que supone el tratarse de una obra de taller local y que tal vez seguía un modelo de taller periférico, lo que podría suponer cierto desfase teórico respecto a la cronología atribuible al modelo originario.

Pero estos hechos no implican necesariamente un desfase cronológico grande, concretamente mayor a una generación. En obras de alta calidad como es ésta, no es lógico aceptar desfases cronológicos si no se precisa el lapso de perduración a través de indicios razonables tales como la evidencia de que los recursos estilísticos o formales utilizados han sufrido una evolución local a partir del teórico modelo introducido desde el ámbito colonial, lo que no es el caso de esta escultura.

La razón teórica de este argumento sería que se introduce y acepta un modelo artístico en tanto en cuanto éste está de moda y, por tanto, dicha introducción en el centro periférico se produce, teóricamente, en un momento de plena vigencia en el centro originario, pues lógicamente nunca se copia lo que está pasado de moda.

El taller o el artesano que adopta un modelo de un lugar periférico sí puede posteriormente repetirlo reiterativamente y producirse así un desfase cro- nológico. Pero en piezas de cierta calidad dicho fenómeno se puede observar. Un artesano que repite la misma escultura llega al amaneramiento $y$, en todo caso, el desfase máximo sería una generación. En un taller, la repetición continuada durante varias generaciones llevaría a un progresivo distanciamiento del modelo original al surgir fórmulas locales en la repetición de los elementos, lo que permite distinguir estilísticamente dicho fenómeno e incluso ordenar cronológicamente, de acuerdo con el mismo, sus productos.

Por último, no se debe olvidar que las circunstancias socioculturales que permiten la introducción de un modelo no tienen por qué ser únicas y pueden repetirse reiterativamente con la introducción de modelos posteriores, lo que también acorta el lapso teórico de perduración (sobre esta problemática, TRILLMICH, 1975, 242-5; ALMAGRO GORBEA, 1983a, 283).

Teniendo en cuenta estas circunstancias, el toro de Monforte del Cid debe considerarse como obra local debida a un artista directamente formado en el ámbito artístico griego oriental cuyas características no ofrecen indicios suficientes para apartarla de la cronología teórica atribuible por motivos estilísticos, por lo que aproximadamente se puede fechar ca. 500 a. de C. y con máxima seguridad entre el 525 y el 475 a. de C.

Este dato cronológico es de enorme trascendencia, pues es uno de los primeros puntos de apoyo que existen para la fijación de la escultura ibérica, especialmente de tipo zoomorfo, siendo evidente que el desconocimiento e imprecisión de las erróneas hipótesis sobre la cronología ha impedido la correcta valoración cultural y la comprensión de este importante campo de la cultura ibérica.

\section{BIBLIOGRAFÍA}

ALMAGRO-GORBEA, M. 1978: «La iberización de las zonas orientales de la Meseta", Ampurias, 38-40.

- 1980: «Arquitectura y sociedad en la cultura ibérica», Colloque International «Architecture et Société de l'Archaisme grec à la fin de la République Romaine. Roma.

- 1982a: «Paisaje y sociedad en las necrópolis ibéricas», XVI Congreso Nacional de Arqueología.

- 1982b: «El paisaje de las necrópolis ibéricas y su interpretación socio-cultural», Homenaje a $N$. Lamboglia en Rivista di Studi Liguri.

- 1982c: «La "colonización" focense en la Península Ibérica», La Parola del Passato, 104-107. 
- 1983a: «Pozo Moro. El monumento orientalizante, su contexto socio-cultural y sus paralelos en la arquitectura funeraria ibérica», Madrider Mitteilungen, 24.

- 1983b: «Pilares-estela ibéricos», Homenaje a M. Almagro Basch, III. Madrid.

- 1983c: «El monumento de Alcoy. Aportación preliminar a la arquitectura funeraria ibérica», Trabajos de Prehistoria, 39.

- 1983d: «Colonizazione e acculturazzione nella Peninsola Iberica. Forme di contatto e processi di transformazione nella società antiche», Atti del Convegno di Cortona, 1981. Pisa-Roma.

AMERICAN ACADEMY IN ROME, 1919, vol. III, 1.

ANDREAE, B. 1962: «Herakles und Alkyoneus», Jahr. des Inst. 77.

ARIAS, P. E. 1962: A History of Greek Vase Painting. London.

AUBET, M. ${ }^{a}$ E. 1979: «Marfiles fenicios del Bajo Guadalquivir. 1. Cruz del Negro», Studia Archaeologica, 52.

AZARPAY, G. 1968: Urartian Art and Artifacts. A Chronological Study, I. Berkeley-Los Ángeles.

BABELON, E. 1900: Traité des monnaies grecques et romaines. París.

BARNETT, R. D. 1975: A Catalogue of Nimrud Ivories in the British Museum. London.

- 1982: Ancient Ivories in the Middle East and adjacent Countries. Qedem 14, Jerusalén.

BLANCO, A. 1960: «Orientalia II», Archivo Español de Arqueología, 33 .

- 1962: «El toro ibérico», Homenaje a C. Mergelina. Murcia.

BOARDMANN, J. 1978: Greek Skulpture. The Archaic Period. London.

BONSOR, G. E. 1899: «Les colonies agricoles pré-romaines de la Vallée du Betis", Revue Archéologique, 35.

- 1928: Early Engraved Ivories in the Colletion of the Hispanic Society of America. New York.

BRANDT, E. 1968: AGDS I. München.

BROMMER, F. 1877: Der Parthenonfries. Mainz.

CAMPOREALE, G. 1977: La tomba del Duce Firenze.

CHAPA, T. 1980: La escultura zoomorfa ibérica en piedra. Tesis Doctoral reprografiada de la Universidad Complutense. Madrid.

- 1982: «Influences de la colonisation phocéenne sur la sculpture ibérique», La Parola del Passato, 104-107.

CLARKE, J. T., BACON, F. H. and KOLDEWEY, R. 1902 Investigations at Assos. London.

COHEN, B. 1978: Attic Bilingued Vases and Their Painters, New York.

COMSTOCK, M. and Vermeule, C. 1971: Greek, Etruscan and Roman Bronzes in the Museum of Fine Arts Boston. New York.

COOK, R. M. 1981: Clazomenian Sarcophagi. Mainz.

COSTE-MESSELIERE, P. de la. 1936: «Au Musée de Delphos», Befar, 138. París.

- 1957a: Delphes. París.

- 1957b: Sculptures du Trésor des Athéniens. Fouilles de Delphes, 4, 4. París.

CRAWFORD, M. H. 1974: Roman Republican Coinage. Cambrigde.

CULLICAN, W. 1970: «Coups à décor phénicien provenant d'Iran», Syria, 47

CURTIS, C.D. 1919: The Bernardini Tomb. Roma.

DAUX, G. 1966: «Chronique des fouilles et découvertes archéologiques en Grèce en 1965», Bulletin de Correspondance Héllénique XC.

DUNHAN, D. S/A: El Kurru, Royal Cemetry of Kush I.
ECHALLIER-MONTENAT, L. 1977: «Nota sobre la procedencia de las rocas utilizadas en las esculturas ibéricas de La Alcudia de Elche», Revista del Instituto de Estudios Alicantinos, 20.

FERNÁNDEZ AVILÉS, A. 1941: «Los toros hispánicos de Cabezo Lucero, Rojales (Alicante)», Archivo Español de Arqueología, 14.

- 1953: «Excavaciones en el Llano de la Consolación (18911946)", Archivo de Prehistoria Levantina, IV.

FERNÁNDEZ CHICARRO, C. 1957: «Hallazgos arqueológicos de la provincia de Jaén», IV Congreso Nacional de Arqueologia (Burgos, 1955).

FILOW, B. D. 1927: Die Archaische Nekropole von Trebenisch te am Ochrida-See. Leipzig.

FRANKE, P. R. und Hirmer, M. 1964: Die Griechische Münze. München.

FURTWANGLER, A. 1900: Die Antiken Gemmen. Berlin.

FURTWÄNGLER, A. E. 1982: «Heraion von Samos: Grabungen in Südtemenos 1977», $A . M$.

GARCÍA Y BELLIDO, A. 1943: La Dama de Elche. Madrid.

- 1971: Iberische Kunst in Spanien. Mainz.

GJERSTAD, E. 1946: «Decorated Metal Bowls from Cyprus», Opuscula Archeologica, IV, 1.

- 1948: Scen, Lund.

GONZÁLEZ NAVARRETE, J. 1987: Escultura ibérica del Cerrillo Blanco, Porcuna, Jaén. Jaén.

HAEBERLIN, J. E. J. 1910: Aes Grave. Frankfurt.

HEILMEYER, W. D. 1976: Frühe Olympische Bronze-figuren. Olympische Forschungen, 12. Berlín.

HELDRING, B. 1981: «Sicilian Plastic Vases», Archeología Traiectina, 15. Utrecht.

HERNÁNDEZ, J. SANCHO, A., y COLLANTES, F. 1951: Catálogo Arqueológico y Artístico de la provincia de Sevilla, III. Sevilla.

HERRMAN, H. V. 1966a: Die Kessel der Orientalisieranden Zeit. Olimpische Forschungen, 6. Berlin.

- 1966b: Urartu und Griechenland.

JENKINS, G. K. 1972: Monnaies grecques. Fribourg.

JUCKER, H. 1966: Bronzehenkel und Bronzehydria in Pesaro. Pesaro.

KARAGEORGIS, V. 1965: Some Cypriote Painters of Bulls in the Archaic Period.

KARAGEORGIS, V. et DES GRAGNIERS, J. 1974: «La céramique chypriote de Style figuré. Age du Fer (1050-500 a. de C.) 》, Bibliotheca di antichitá Cipriote, 2. Roma

KARDARA, C. P. 1978: «Oriental Influences on Rhodian Vases", Les céramiques de la Grèce de l'Est et leur diffusion en Occident. París.

KONTOLEAR, N. M. 1965: Archaiske Zophoros ex parou Charisterion eis $A$ Orlandos, $I$. Atenas.

KUBLER, K. s/a: Kerameikos, V, 1.

KUKAHN, E. 1973: «Una aplicación de una kratera de bronce griega», XII Congreso Nacional de Arqueología.

KUNZE, E. s/a: Kretische Bronzereliefs.

LANGLOTZ, E. 1963: Die Kunst der Westgriechen. München.

- 1966: Die Kulturell und Kunstlerische Hellenisierung der Küsten des Mittelmeers durch die Stadt Phokaia. Köln.

MALLOWAN, M. and DAVIES, L. G. 1970: Ivories from Nimrud II. Aberdeen.

MALLOWAN, M. and HERRMAN, G. 1974: Ivories from Nimrud III. Aberdeen.

MAXIMOVA, M. I. 1977: Les vases plastiques dans l'Antiquité. París.

MINTO, A. 1960: Il vaso François. Firenze.

MOORTGAT, A. 1940: Vorderasiatische Rollsiegel. Berlín. 
MOROTE, G. 1979: «El trazado de la Vía Augusta desde Tarragona a Carthagine Spartaria. Una aproximación a su estudio», Saguntum, 14.

MOT, J. de 1909: «Vases égéens en forme d'animaux», Revue Archéologique, 4, 2.

NICOLINI, G. 1973: Les lbères. Paris.

OPPENHEIM, M. F. von. 1931: Der Tellhalf. Leipzing.

PARETTI, A. L. 1947: La Tomba Regolini-Galassi. Cittá del Vaticano.

PARIS, P. 1903: Essai sur l'art et l'industrie de l'Espagne primitive. Paris.

PAYNE, H. 1931: Necrocorinthia. Oxford.

PFUHL, E. und MOBIUS, H. 1977: Die ostgriechischen Grabreliefs, I. Mainz.

RAMOS, R. 1974: De Helike a Illici. Alicante.

- 1975: La ciudad romana de Illici. Alicante.

RAMOS, A. e/p: La escultura ibérica. Alicante.

REGLING, K. 1924: Die Antike Münze als Kunstwek. Berlín.

REMESAL, J. 1975: "Cerámicas orientalizantes andaluzas», Archivo Español de Arqueología, 48.

RICHTER, G. M. 1950: The Sculpture and sculptures of the Greeks. New Haven.

ROLlEY, C. 1967: Monumenta Graeca et Romana, V, I. Die Bronzen. Leiden.

RUMPF, A. 1927: Chalkidische Vasen. Berlín.

SALVIAT, F. 1978: «La céramique de Style Chiote à Tassos», Céramiques de la Grèce de l'Est et leur diffusion en Occident. París.
SCHEFOLD, K. 1971: Früggriechische Sagenbilder. München. SCHEURLEER, C. W. L. 1936: Grieksche Ceramik, Rotterdam.

SCHIERING, W. s/a: Werkstätten orientalisieschen Keramik aus Rhodas. Berlín.

- 1958: «Der Kalbträger», Opus Nobile, 11. Bremen.

SCHUCHART, W. H. 1940: Archaische Giebelkompositionen. Freiburg.

SCHWALTZ, B. 1980: Metallfiguren aus dem Kabirienheilligtum bei Theben. Berlín.

SILLIERES, P. 1977: "Le "Camino de Hanibal”", Mélanges de la Casa de Velázquez, 23.

SZANTO, E. 1890: «Das Kabirienheiligtum bei Theben», Ath. Mitteilungen, 15.

TREU, G. 1897: Olympia III. Die Bildwerke. Berlín.

TRILLMICH, W. 1975: «Ein Kopfragment aus Verdolay bei Murcia. Zur Problematik der Datierungerischer Grossplastk aufgrund Griechischer Vorbilder», Madrider Mitteilungen, 16.

VIVES Y ESCUDERO, A. 1924: La moneda hispánica. Madrid. WALTER-KARYDI, E. 1973: Samische Gafässe des 6. Jahrhunderts v. Chr. Samos, VI, 1. Bonn.

WOLTERS, P. und BRUNS, G. 1940: Das Kabirienheiligtum bei Theben. Berlín.

ZAZOFF, P. 1968: Etruskische Skarabäen. Mainz.

- 1970: AGDS III. Wiesbaden-Göttigen.

- 1975: AGDS IV, Hannover und Hamberg. MünchenHannover.

ZWIERLEIN-DIEHL, E. 1969: $A G D S / 1$. Berlín-München. 